\title{
Effect of Social Stories on Social Skills of children with Autism Spectrum Disorder
}

\author{
Anu Aggarwal ${ }^{1}$, Babita Prusty $^{2}$
}

\section{ABSTRACT}

The research titled "Effect of Social Stories on social skills of children with Autism Spectrum Disorder" was aimed to study that how Social Stories as an intervention affect the social skills of children with Autism Spectrum Disorder. In the study a sample of 4 children with Autism Spectrum Disorder ranging from 4-8 years of age was taken using purposive sampling. The tool used to assess the social skills was Childhood Autism Rating Scale, Second Edition - Standard Version (CARS2-ST). The data was collected using Pre-Post Research Design and then analyzed using t-test as the statistical tool. There was significant difference between the scores of pre intervention and post intervention by Social Stories. The results hence generated proved that social skills including relating to people, adaptation to change, visual response, listening response and verbal communication can be enhanced and supported by the Social Stories.

Keywords: Autism Spectrum Disorder; Social Stories

Social skills are the fundamental aspect of our day to day life. Social interaction with other people describes our personality and exchange of thoughts with others. Social skills can include how the child relate with others, maintains eye contact with others, his listening response, how he will react to new social situation, ability to understand what the other people says, how he expresses his thoughts or feelings and many more. Social skills are the connection to the world. Children with Autism Spectrum Disorder are excluded with social skills which makes them separate from others. They do not able to understand the social situation and not able to connect with the surrounding. Social stories have been found as a great effort of intervention by psychologists, special educators and therapists to improve social skills of special children. Social story is the ladder for the children with Autism Spectrum Disorder. It aims to support them by giving an idea of a social situation and other people's perspectives. Social stories were developed to make an understanding of social situation and to increase the ability of social interaction.

${ }^{1}$ MA, Clinical psychology, Amity University, Noida

${ }^{2}$ Assistant Professor, Amity University, Noida

(C) 2015 I A Aggarwal, B Prusty; licensee IJIP. This is an Open Access Research distributed under the terms of the Creative Commons Attribution License (http://creativecommons.org/licenses/by/2.0), which permits unrestricted use, distribution, and reproduction in any Medium, provided the original work is properly cited. 


\section{Operational definition of Variables}

Michelson, Sugai, Wood and Kazdin (1983) operationalize the definition of Social Skills within the constructs of Social Learning Theory as follows:

Social skills (a) are primarily acquired through learning (e.g., observation, modeling, rehearsal and feedback); (b) comprise specific and discrete verbal and non verbal behaviors; (c) entail both effective and appropriate initiations and responses;(d) Maximize social reinforcement (e.g., positive responses from one's social environment); (e) are interactive by nature and entail both effective and appropriate responses (e.g., reciprocity and timing of specific behaviors); and (f) performance is influenced by the characteristics of [participants and environments in which it occurs. (e.g., situational specificity.)

According to DSM V, Autism is a complex and serious neurological disorder which leads to deficits in social communication and social interaction. It also includes restricted, repetitive patterns of behavior, interest or activities. The symptoms must be present in early developmental period and can cause significant impairment in social, occupational or other important areas of functioning.

Definition of Autism by Ritvo and Freeman (1978), Autism Society of America (2004), which is closely aligned with the criteria, used in the DSM-IV-TR (APA, 2000) and Kanner's (1943) original observations of autism:

"A Social Story describes a situation, skill, or concept in terms of relevant social cues, perspectives and common responses in a specifically defined style and format" (Gray. 2004).

\section{- Social stories}

Social stories can be used on preschool age to adult with moderate cognitive ability to average intelligence. Social Stories are an easy to implement. Widely used strategy which impact challenging behavior in autistic individuals. A social story is an individualized cognitive intervention that describes the salient social cues and appropriate responses associated with the particular situation.

Social stories were first introduced as an intervention by Carol Gray in 1991. Research conducted by the NAC $(2009 a, 2009 c)$ indicates that there is enough empirical support to consider them as an established treatment for children with autism and AS age to 6-14 years. "A Social Story describes a situation, skill, or concept in terms of relevant social cues, perspectives and common responses in a specifically defined style and format" (Gray. 2004). One of the most common misconception regarding Social Stories focus on the underlying causes of the child's frustrations and attempt to increase his or her understanding of events and expectations. 
Social stories are written by professionals or parents to describe social situations that are difficult to understand and may be confusing for children with autism. Each story is develop according to considerations of child's abilities and learning style of children which describes relevant social cues and desired responses to target situation. A variety of materials and instructional methods can be used to make social stories understandable.

Social stories are applicable to home, school, and community settings- any situation that may occur in these environment is a potential social story topic (Gray et al., 1993). Social stories are useful for identifying relevant social cues, introducing new routines and rules, and positively defining desired social skills. At home, parents may decide to write a social story to prepare their child for an upcoming event, such as visit to a relative or a family vacation, or to introduce a new daily routine which makes easy for child to ready for change or adaptation to change. In addition, social stories in the school setting can prepare a child for unexpected situations such as change of class rooms, addition of new children to class, substitute teachers, fire drills, or school closings. In a community setting, social stories identify naturally occurring cues and events to provide structure to a situation that is otherwise overwhelming to a child. In any setting, social stories introduce the possibility of unexpected occurrences in such a way that variation is a part of any routine or situation. Whatever the situation they describe or the social skills they address, social stories are written to assist a child in more accurately understanding and responding to a target social situation. Social stories prepare the children to adapt the change calmly in any environment whether in home, school or community settings.

Gray (1994) identified several uses for social stories: (1) describing a situation, including social cues and responses; (2) personalizing social skills instruction; (3) teaching routines or student adjustment to routine changes; (4) teaching academic material in a realistic social setting; and (5) addressing challenging behaviors such as aggression, obsessive behavior and fear.

Visual supports are an important component of any teaching program developed for children and adults with autism. Both children and adults appear to benefit from the use of supports. Visual supports are introduced into their daily lives in order to augment language and let them know what is happening around them. People with autism have difficulty processing verbal information or using speech to communicate. While they have difficulty with auditory processing, their visual abilities appear to be one of their relative strengths and they understand respond more effectively to visual stimuli than to auditory stimuli.

Social skills deficits which are present in Children with Autism Spectrum Disorder are as follows:

Fundamental skills are required for effective communication. Eye contact, suitable volume, as well as appropriate facial expressions is key to positive social relations. These behaviors do not come naturally or easily for many children with Autism Spectrum Disorders. Limited use of 
these skills as well as misunderstanding their importance leads to misperception and misinformation. Without these basic skills individuals can miss important cues.

Social initiation skills involve approaching another person to start a communication or social interaction. They are difficult for children with autism, who tend to be shy and fail to recognize when these skills are useful. Typical social initiation skills include greeting, starting a conversation, entering a conversation, giving a compliment, inviting someone to play or asking for help.

Social response skills are used in response to a verbal or non verbal communication or interaction initiated by someone else, or in response to an event in the environment. Social response skills include acknowledging others, following directions, staying on task, waiting or offering help or encouragement. The child must be able to "read" the person's body language and correctly interpret what is said to be able to respond appropriately.

Getting along with other includes the skills necessary to foster positive relationships. They require a certain amount of reciprocity, or being able to adjust personal behavior to relate to what another person is saying or doing. Children with ASD do not understand the social rules of reciprocity.

Major characteristics and problem areas of ASD which impact their social life:

\begin{tabular}{|c|c|}
\hline CHARACTERSTICS & POSSIBLE PROBLEM AREAS \\
\hline Social interaction deficits & $\begin{array}{l}\text { - Lack of joint attention } \\
\text { - May not respond to name and may be } \\
\text { appear deaf. } \\
\text { - Oblivious to others and appears to be in } \\
\text { own world. } \\
\text { - Little or no eye contact. } \\
\text { - No reciprocal friendships. } \\
\text { - May treat people as objects. } \\
\text { - Resistance to being cuddled or touched. }\end{array}$ \\
\hline Cognitive and perceptual challenges & $\begin{array}{l}\text { - Literal, restricted and inflexible } \\
\text { patterns of thinking. } \\
\text { Tendency to over select irrelevant } \\
\text { stimuli in environment and not focus on } \\
\text { relevant stimuli. } \\
\text { - Obsessive need for sameness, } \\
\text { resistance to change. } \\
\text { - Exhibits problem with social cognitions } \\
\text { - Lack of motivation and curiosity about } \\
\text { the environment. } \\
\text { - Lack imagination and appropriate play. }\end{array}$ \\
\hline
\end{tabular}


Various research studies have been done on management or intervention of Social stories for Children with Autism Spectrum Disorders. Most of the studies focused on improving and maintaining the social skills of children by providing intervention of Social Stories. The literature review presents the published researches of past 18 years.

A study was done by N.J. Bell in 2005 to evaluate the effectiveness of social stories as an intervention. The aim of the study was to analyze the effect of social stories on autistic children without giving any other intervention to them. Three children diagnosed with autism were the participants of the research. It has been found that the one child improved his on task behavior by pictorial version of the social story and may have facilitated maintenance for the second participant. The above result indicates that the social stories are helpful and acting as push up button for going towards the appropriate behaviors in social situations. Social stories are the strongest precursor for the self- management. The result of the study states that the social proved to be effective to increase on task behaviors of three children with autism.

Reichow and Sabomie in 2009 did study which focused to analyze the effect of social stories on verbal greetings initiation of autistic children. Social stories are used to decrease the social deficits of autistic children. Verbal greetings initiation is a part of social skills. A young 11 year old boy diagnosed with High Functioning Autism was participant. A comparative study was done with social stories intervention and withdrawal of social stories intervention. Improvement in verbal greetings initiation was observed in both intervention conditions as compared to baseline conditions. The result of the study indicated that the social stories can also be effective in increasing verbal greeting initiations in autistic children. Intervention was continued with visual supports after the study to maintain the desired behavior.

A classic recent research was done by Thiemann and Goldstein in February 2013. Visual cues plays vital role in improving social communication skills in autism. In this study, written text and pictorial cuing (social stories) with supplemental video feedback was investigated to know the effects on social communication of autistic children. The participants were 5 children with social impairment and 10 of their peers without disabilities ( 2 from each focus child's classroom) from one elementary school. The experiments were done in a triad, consisting of 1 child with social impairments and 2 peers without disabilities. The mean age of focus children range from 6 years to 12 years. Treatment was implemented twice per week and consisted of 10 min of systematic instruction using visual stimuli, $10 \mathrm{~min}$ of social interaction, and $10 \mathrm{~min}$ of self-evaluation using video feedback. Results showed increases in targeted social communication skills when the treatment was implemented. Some generalized treatment effects were observed across untrained social behaviors, and 1 participant generalized improvements within the classroom. The strength which combined social stories, pictorial and written text cues with supplemental video feedback gives a positive or effective change in social communication skills of 5 young students with autism or social impairment. 


\section{METHOD}

\section{Objective}

To assess and examine the change in social skills (Relating to people, Adaptation to change, Visual response, Listening response and Verbal Communication) by giving the intervention of Social Stories in children diagnosed with Autism Spectrum disorder.

\section{Hypothesis}

Based on objective, following hypothesis has been formulated:

- Social stories will support and enhance the social skills in Children with Autism Spectrum Disorder.

\section{Sample}

With means of purposive sampling, 4 children, from age group 4-8 yrs were carefully selected before inclusion. The common deficits of the participants were initiating conversation, maintaining eye contact, and certain odd behaviors in social situation as observed before initiating the study. Meaningful speech is absent in all participants. Echolalia was the major symptom which was clearly observed.

- Sample Size: 4

- Sampling Method : Purposive Sampling

- Sampling Source: Samvedna (Centre for Rehabilitation)

\section{Inclusion criteria}

- $\quad$ Age ranging from 4-8 yrs

- Children diagnosed with Autism Spectrum Disorder

- Both boys and girls.

\section{Exclusion criteria}

- Those who are receiving any other intervention pertaining to Visual Supports.

- Suffering from any other major physical problems

- Suffering from any other Psychiatric disorders like Mental Retardation etc.

\section{Description of the tools employed}

\section{Childhood Autism Rating Scale, Second Edition (CARS2)}

CARS2-ST has been used for assessing the children with Autism Spectrum Disorders in our research. The 15 items in the scale are: Relating to people; Imitative behavior; Emotional response; Body use; Object use; Adaptation to change; Visual response; Listening response; 
Perceptive response; Fear or anxiety; Verbal communication; Non-verbal communication; Activity level; Level and consistency of intellective relations; General impressions.

The scoring of CARS2-ST is done on 4 point rating scale which are categorize in 7 ratings from normal to severely abnormal limits of range. The below 7 allowable ratings for each item are as follows:

1. Within normal limits for that age

1.5 Very mildly abnormal for that age

2 Mildly abnormal for that age

2.5 Mildly -to- moderately abnormal for that age

3 Moderately abnormal for that age

3.5 Moderately-to- severely abnormal for that age

4 Severely abnormal for that age

\section{Research Design}

According to the objective and formulated hypothesis Pre- Post Research Design will be used to analyze the Effect of Social Stories on Social skills of children with Autism Spectrum Disorder.

\section{Statistical Analysis}

The student's $\mathrm{t}$ - test was used to find the significance and comparing the Pre- Post intervention effect on selected participants.

\section{Procedure}

- With means of purposive sampling, the sample was selected who are diagnosed with Autism Spectrum Disorder, ranging from 4-8 years of age. The sample was selected with the help of Occupational Therapist. It comprised of 3 boys and 1 girl. They were carefully observed and selected before inclusion.

- The CARS was administered and intervention was provided with the informed consent of Occupational Therapists and parents of the children.

- The total number of sessions including the rapport building and intervention procedure are 37. Each session was taken for 45 minutes. The rapport was built by playing with the children in different activities like puzzle, flip-flop cards, beads etc.

- After building rapport and debriefing to parents, Childhood Autism Rating Scale was administered to know the current status and mental examination of children. Scoring of 
pre- intervention phase of CARS was done. According to the pre - intervention scores and brief interview with the parents, Social Stories were developed.

- Social stories were made according to the social deficits common in all 4 children. Two social stories were made to enhance the interaction with others and how to deal with the surroundings by controlling self.

- One of the social stories is based on undesirable behavior of touching things of others without taking permission. It has been observed by the parents that children touch and take things of others without taking permission. This social story is presented with cards and real things which are generally present in the surroundings. Firstly, the cards were presented with verbal prompts and meanings, and then it was practiced and rehearsed by real objects by statements like do not touch and take permission.

- Other social story is formulated on the deficit of initiating conversation with others. Social story explains the social situation and children were asked to answer the questions asked by others. It was rehearsed by role play with others. Both social stories were presented in 30 sessions with a 5 minute interval of each session.

- Social stories were presented daily till 30 sessions; parents were also instructed to make their children learn about social stories at home also. Parents were asked about the behavior of their child at home settings or in any other social situation if occurred. After giving intervention of 30 days, the post intervention scoring of CARS was done to know the effect of social stories.

\section{DATA TABLES AND FIGURES}

The study aimed at examining the effect of social stories on social skills of children with Autism Spectrum Disorder.

The results of the investigation are as follows:

Table 1 represents the scores obtained for Relating to People by Pre intervention and Post intervention of Social Stories

\begin{tabular}{|l|l|l|l|l|l|l|l|l|}
\hline ITEM & PHASE & N & Mean & $\begin{array}{l}\text { Std. } \\
\text { Deviation }\end{array}$ & $\begin{array}{l}\text { Std. } \\
\text { Error } \\
\text { Mean }\end{array}$ & df & t-value & $\begin{array}{l}\text { Level of } \\
\text { significance }\end{array}$ \\
\hline $\begin{array}{l}\text { Relating to } \\
\text { people }\end{array}$ & $\begin{array}{l}\text { Pre } \\
\text { interventio } \\
\mathbf{n}\end{array}$ & 4 & 2.5 & 0.7071 & .3535 & & & \\
\cline { 2 - 8 } & $\begin{array}{l}\text { Post } \\
\text { interventio } \\
\mathbf{n}\end{array}$ & 4 & 2 & 7.4939 & .2041 & 2.4494 & .05 \\
\hline
\end{tabular}


The table 1 shows mean, standard deviation, standard error mean, $t$-values and the significant values of Pre intervention and Post intervention of Social Stories. As seen Deficit in Social Skill: Relating to people is high in pre intervention $(\mathrm{n}=4$, mean $=2.5)$ as compared to post intervention $(n=4$, mean $=2$ ) of social stories. There is difference between pre intervention and post intervention scores of Relating to People(t value-2.449) which is significant at .05.

Figure 1 Bar diagram showing the comparison between Pre intervention and Post intervention of Social stories on Social skill: Relating to people

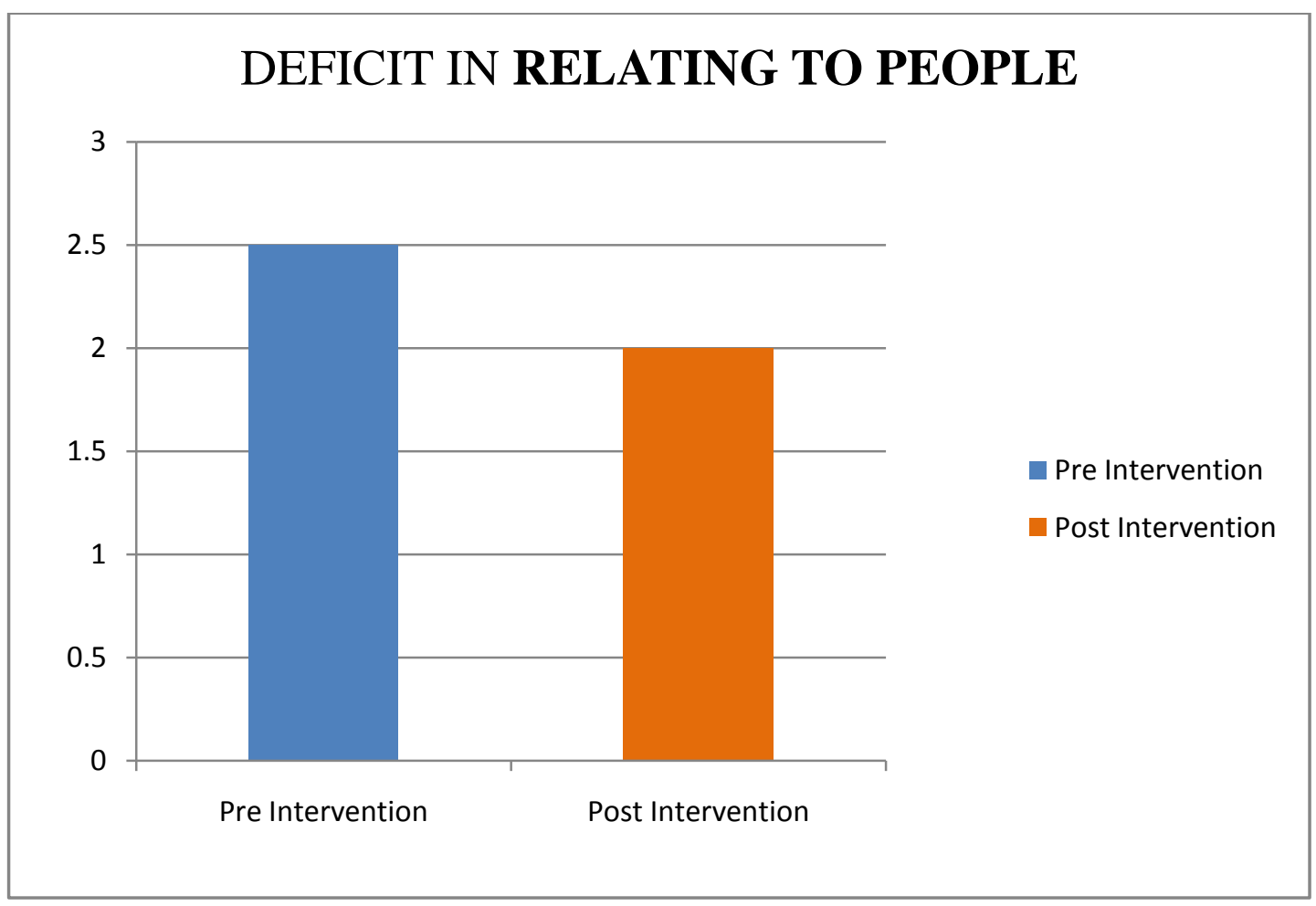


Table 2 represents the scores obtained for Adaptation to Change by Pre intervention and Post intervention of Social Stories

\begin{tabular}{|l|l|l|l|l|l|l|l|l|}
\hline ITEM & PHASE & N & $\begin{array}{l}\text { Mea } \\
\mathbf{n}\end{array}$ & $\begin{array}{l}\text { Std. } \\
\text { Deviation }\end{array}$ & $\begin{array}{l}\text { Std. } \\
\text { Error } \\
\text { Mean }\end{array}$ & df & t-value- & $\begin{array}{l}\text { Level of } \\
\text { significance }\end{array}$ \\
\hline \multirow{2}{*}{$\begin{array}{l}\text { Adaptation } \\
\text { to change }\end{array}$} & $\begin{array}{l}\text { Pre } \\
\text { intervention }\end{array}$ & 4 & 2.25 & .8660 & .4330 & & & \\
\cline { 2 - 7 } & $\begin{array}{l}\text { Post } \\
\text { intervention }\end{array}$ & 4 & $\begin{array}{l}1.87 \\
5\end{array}$ & 0.4330 & .3145 & 3 & 3 & .05 \\
\hline
\end{tabular}

The table 2 shows mean, standard deviation, standard error mean, t-values and the significant values of Pre intervention and Post intervention of Social Stories. As seen Deficit in Social Skill: Adaptation to change is high in pre intervention $(n=4$, mean $=2.25)$ as compared to post intervention $(n=4$, mean $=1.875)$ of social stories. There is difference between pre intervention and post intervention scores of Adaptation to Change ( $\mathrm{t}$ value-3) which is significant at 05 .

Fig.2 Bar diagram showing the comparison between Pre intervention and Post intervention of Social stories on Social skill: Adaptation to change

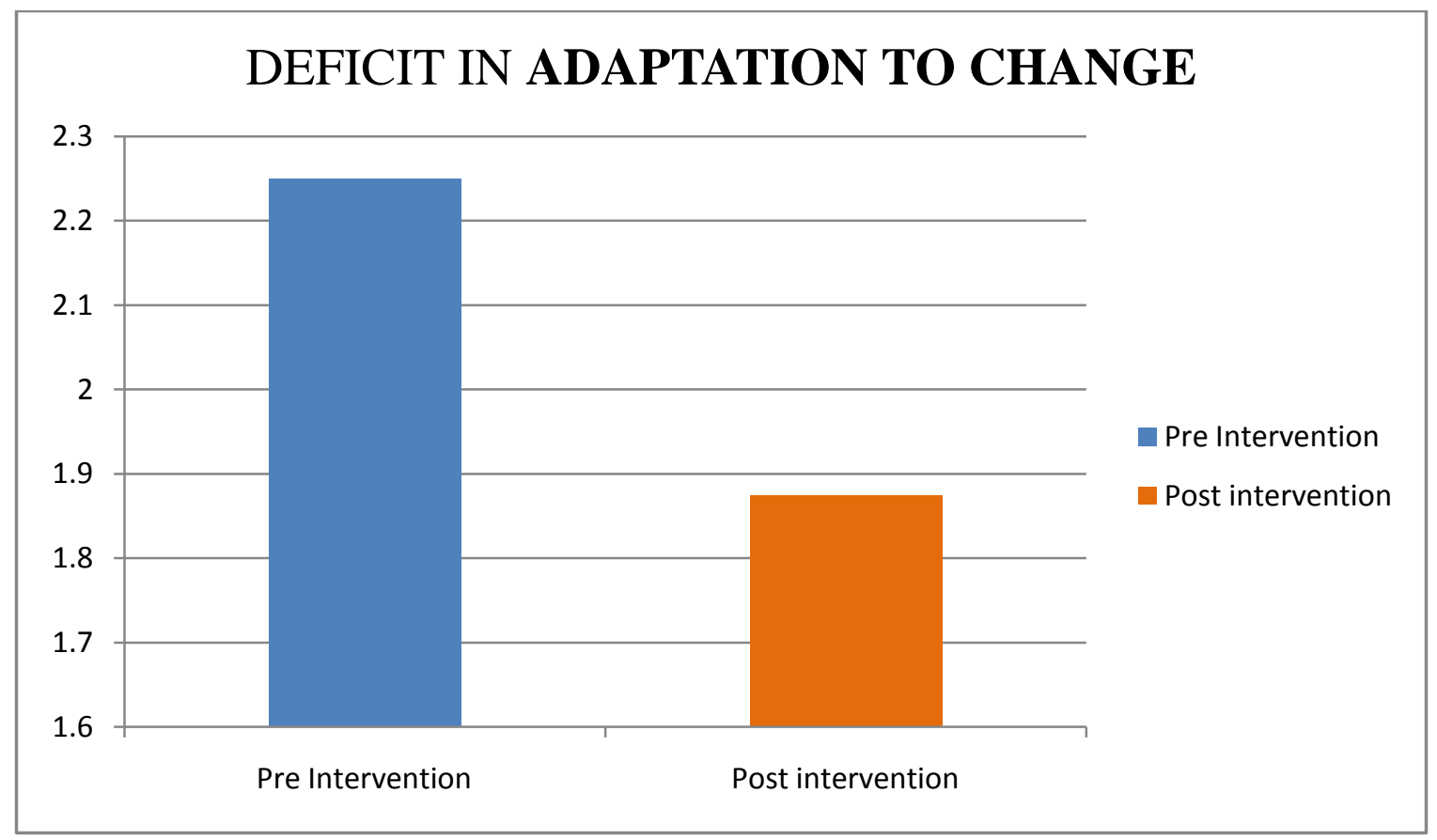


Table 3 represents the scores obtained for Listening Response by Pre intervention and Post intervention of Social Stories

\begin{tabular}{|l|l|l|l|l|l|l|l|l|}
\hline ITEM & PHASE & $\mathbf{N}$ & Mean & $\begin{array}{l}\text { Std. } \\
\text { Deviation }\end{array}$ & $\begin{array}{l}\text { Std. } \\
\text { Error } \\
\text { Mean }\end{array}$ & df & t-value- & $\begin{array}{l}\text { Level of } \\
\text { significance }\end{array}$ \\
\hline \multirow{2}{*}{$\begin{array}{l}\text { Listening } \\
\text { response }\end{array}$} & $\begin{array}{l}\text { Pre } \\
\text { intervention }\end{array}$ & 4 & 2.5 & 0.4082 & .2041 & & & \\
\cline { 2 - 7 } & $\begin{array}{l}\text { Post } \\
\text { intervention }\end{array}$ & 4 & 1.75 & .2886 & .1443 & 3 & 3 & .05 \\
\hline
\end{tabular}

The table 3 shows mean, standard deviation, standard error mean, $t$-values and the significant values of Pre intervention and Post intervention of Social Stories. As seen Deficit in Social Skill: Listening response is high in pre intervention $(n=4$, mean $=2.5)$ as compared to post intervention $(n=4$, mean $=1.75)$ of social stories. There is difference between pre intervention and post intervention scores of Listening Response ( $t$ value-3) which is significant at 05 .

Fig.3 Bar diagram showing the comparison between Pre intervention and Post intervention of Social stories on Social skill: Listening response

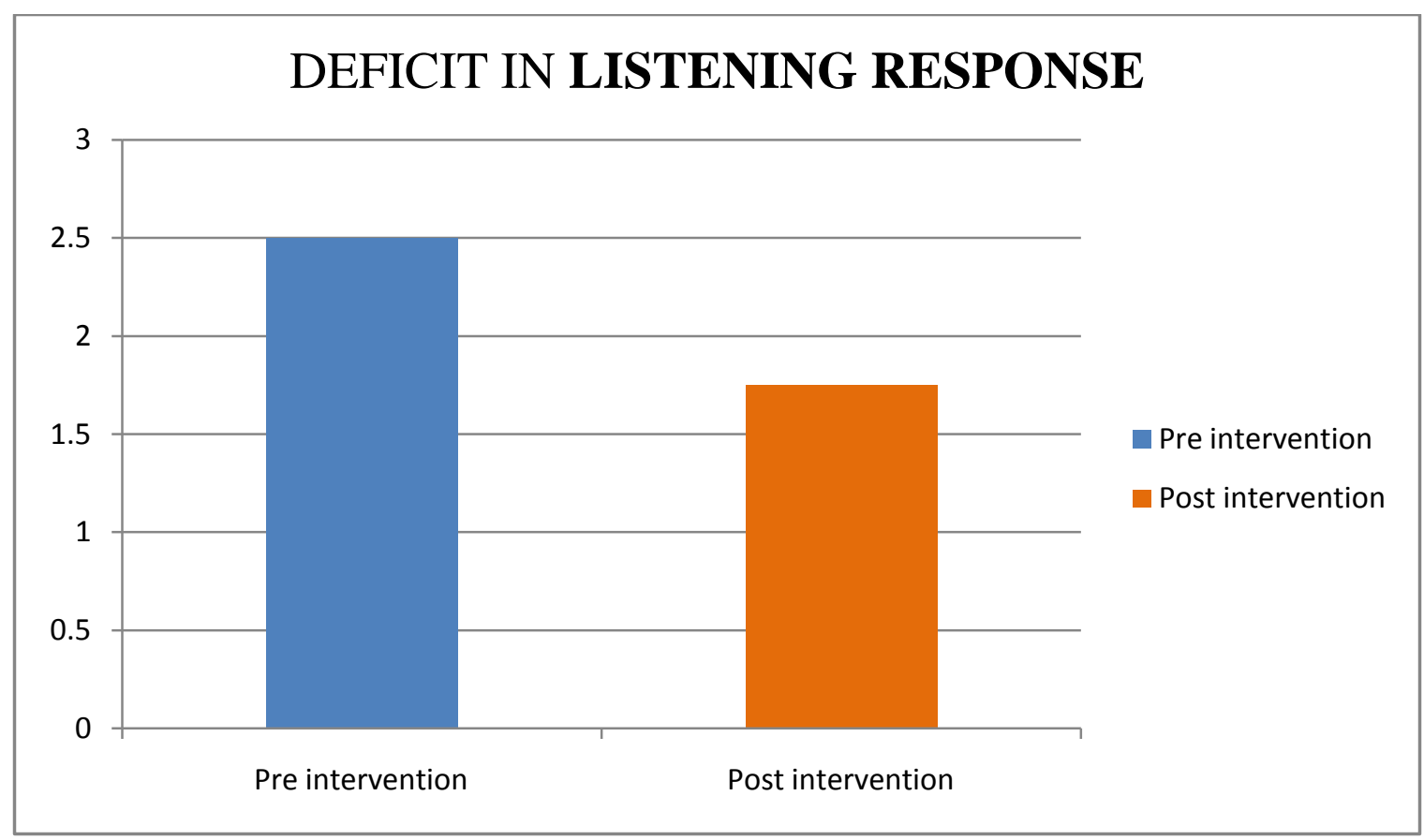


Table 4 represents the scores obtained for Visual Response by Pre intervention and Post intervention of Social Stories

\begin{tabular}{|l|l|l|l|l|l|l|l|l|}
\hline ITEM & PHASE & $\mathbf{N}$ & Mean & $\begin{array}{l}\text { Std. } \\
\text { Deviation }\end{array}$ & $\begin{array}{l}\text { Std. } \\
\text { Error } \\
\text { Mean }\end{array}$ & df & t-value- & $\begin{array}{l}\text { Level of } \\
\text { significance }\end{array}$ \\
\hline \multirow{2}{*}{$\begin{array}{l}\text { Visual } \\
\text { response }\end{array}$} & $\begin{array}{l}\text { Pre } \\
\text { intervention }\end{array}$ & 4 & 2.5 & 0.4082 & .2041 & & & \\
\cline { 2 - 7 } & Post & 4 & 1.625 & .25 & .125 & 3 & 7 & .05 \\
\hline
\end{tabular}

The table 4 shows mean, standard deviation, standard error mean, t-values and the significant values of Pre intervention and Post intervention of Social Stories. As seen Deficit in Social Skill: Visual response is high in pre intervention $(n=4$, mean $=2.5)$ as compared to post intervention $(n=4$, mean $=1.625)$ of social stories. There is difference between pre intervention and post intervention scores of Visual Response ( $t$ value-7) which is significant at .05 .

Fig.4 Bar diagram showing the comparison between Pre intervention and Post intervention of Social stories on Social skill: Visual Response

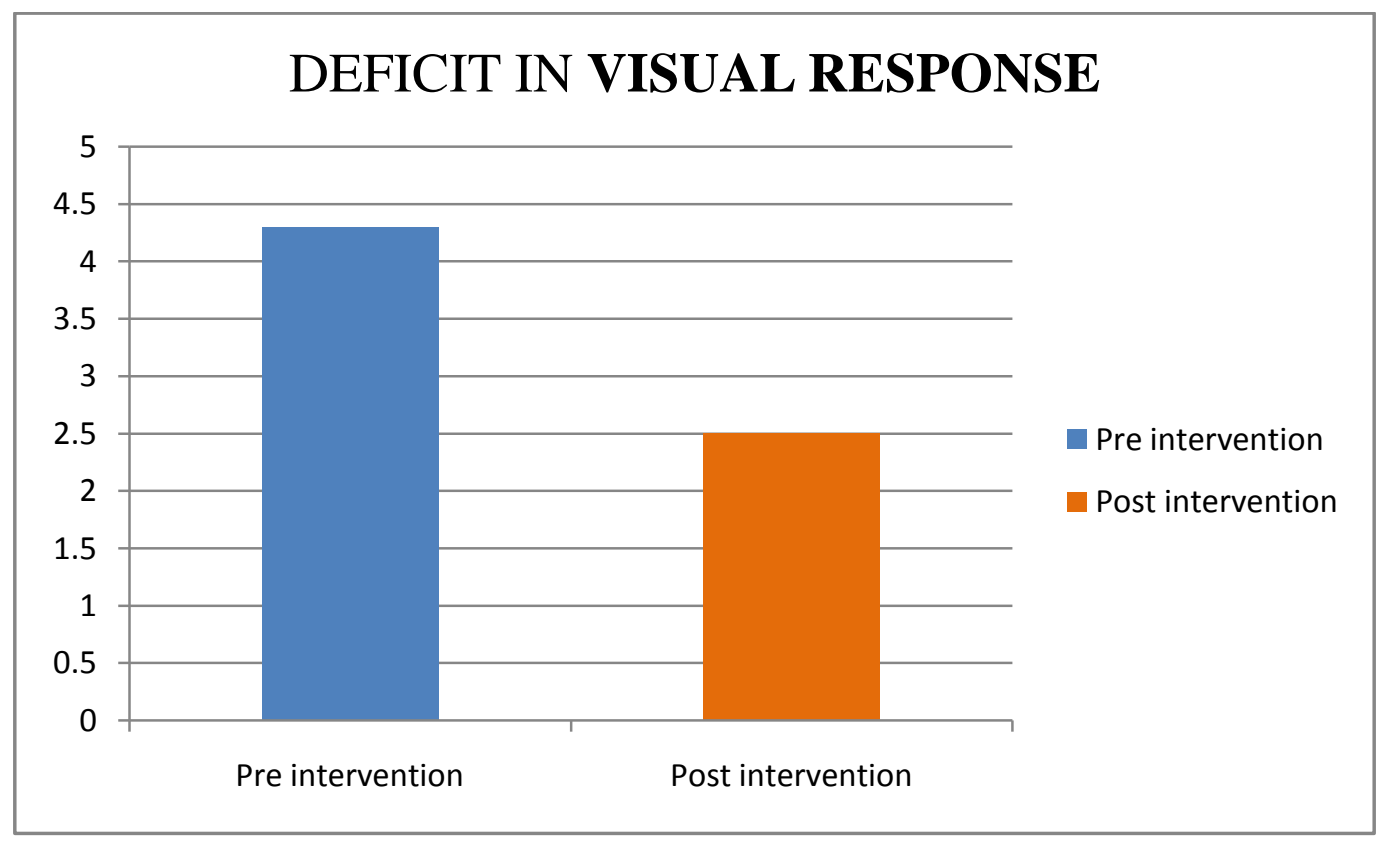


Table 5 represents the scores obtained for Verbal Communication by Pre intervention and Post intervention of Social Stories

\begin{tabular}{|l|l|l|l|l|l|l|l|l|}
\hline ITEM & PHASE & N & Mean & $\begin{array}{l}\text { Std. } \\
\text { Deviation }\end{array}$ & $\begin{array}{l}\text { Std. } \\
\text { Error } \\
\text { Mean }\end{array}$ & df & t-value- & $\begin{array}{l}\text { Level of } \\
\text { significance }\end{array}$ \\
\hline \multirow{2}{*}{$\begin{array}{l}\text { Verbal } \\
\text { communic } \\
\text { ation }\end{array}$} & $\begin{array}{l}\text { Pre- } \\
\text { intervention }\end{array}$ & 4 & 2.875 & .25 & .125 & & & \\
\cline { 2 - 6 } & Post & 4 & 2.25 & .2886 & .1443 & 3 & 5 & .05 \\
\hline
\end{tabular}

The table 5 shows mean, standard deviation, standard error mean, t-values and the significant values of Pre intervention and Post intervention of Social Stories. As seen Deficit in Social Skill: Verbal Communication is high in pre intervention $(n=4$, mean $=2.875)$ as compared to post intervention $(n=4$, mean $=2.25)$ of social stories. There is difference between pre intervention and post intervention scores of Verbal Communication ( $t$ value-5) which is significant at .05.

Fig.5 Bar diagram showing the comparison between Pre intervention and Post intervention of Social stories on Social skill: Verbal Communication

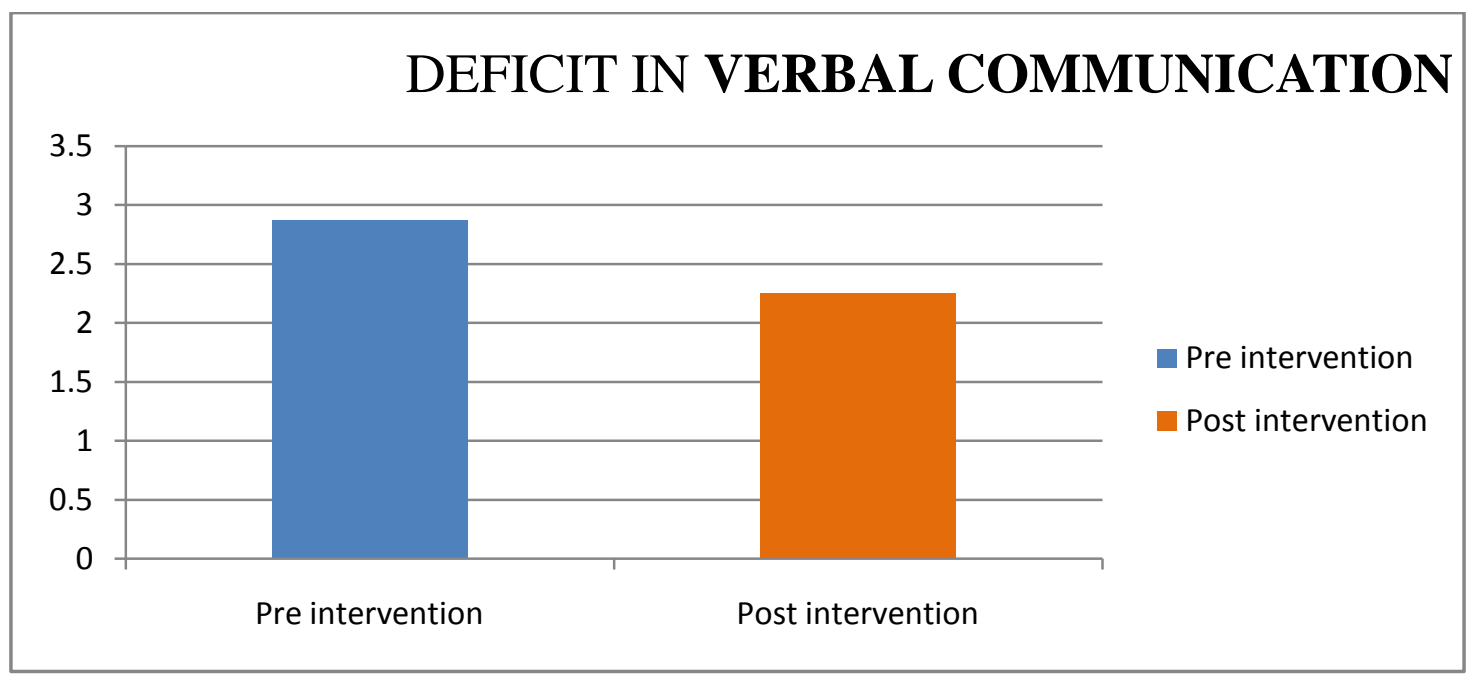




\section{DISCUSSIONS}

The present study was carried out to examine the change in social skills of children with Autism Spectrum Disorder by giving the intervention of Social story. The study is a comparative study between Pre intervention and Post intervention by using social stories. The data was collected on 4 samples, ranging from 4-8 years of age and diagnosed with Autism Spectrum Disorder. The independent variable for the research was Social Stories and the dependent variable was rate of improvement in Social skills. On the basis of this, it was hypothesized that: "Social stories will support and enhance the social skills in Children with Autism Spectrum Disorder".

From the analysis of Table 1 and Fig. 1 it is seen that there is significant difference between pre intervention and post intervention of Social Skill: Relating to people by using social stories.

It has been observed from the Fig. 1 that the difference between two means of pre intervention and post intervention was significant and it shows that the deficit in relating to people is less in post intervention as compared to pre intervention. It signifies that Social Skill: Relating to people can be enhanced by intervention of social stories. This result is also supported by one of the previous research done by Crozier and Tincani (2005). The target behavior of "talking to people" of 8 year old boy was improved by social stories with verbal prompts. The study was divided into two designs (a) intervention of social stories without any modification and (b) intervention of social stories with modification of verbal prompts. ABAC design was used in the research. Observations were made by his teachers and his family members. The decrease in disruptive behaviors has been observed more in second intervention phase i.e. social stories with modification of verbal prompts as compared first intervention phase of social story only.

Another pioneering study was done by Barry and Burlew (2004) also contribute to the present study. The study was done to enhance the play skills and social interaction of Autistic children through Social Stories. The participants were 2 children with severe autism with little expressive language. The results were surprising as both of the children stared taking initiative in play and improvement in their communication skills has also been observed. This research proved that social stories can also be effective for the severe autistic children with little language skills.

One of the social stories of present research includes the initiation of conversation by answering question to others which covers relation or interaction with people. It has been clearly observed during the sessions and by parents that their children could answer some of the basic questions which are related to the needs of themselves, for example "How are you?" "What did you have in your lunch?”. One of the participants did not show any significant improvement.

Use of social stories as an intervention can increases the social interaction of children with Autism Spectrum Disorder towards peers both with and without disabilities (Scattone and Tingstorm; 2011).Improvement in verbal greetings initiation was observed in children with 
Autism Spectrum Disorder by providing the intervention of Social Stories (Reichow and Sabomie, 2009).

Further from the analysis of Table 2 and Fig 2, it is seen that the there is significant difference between the Pre intervention and Post intervention of Social skill: Adaptation to Change by using social stories. It can be observed in the Fig 2 that difference between two means of pre intervention and post intervention is significant. This shows that deficit in Social Skill: Adaptation to change is less in pre intervention as compared to post intervention. It signifies that the social skill of adaptation to change can be enhanced by social stories. Social stories developed for the research also includes social skill of adaptation to change. They explain new things which are present in our surroundings and children with Autism Spectrum disorder faces difficulty to deal with them or may indulge in maladaptive behavior with new things or new environment. Social stories help children and make them learn about the new things and how to deal with it in socially acceptable behavior.

It has been observed that the children were now able to cope up the changes in the environment. Now, they were able to understand that what type of things they should touch and how should they deal with the surroundings by not touching things of others. They were learned to ask permission from elders to touch or to have a particular thing. It has been clearly observed through sessions that children now ask permission before touching a new thing. Parents also observed and share their feelings of improvement in their children. One of the participants did not show any magnificent improvement in adaptation to change.

The analysis of Table 3 and Fig 3 shows that there is significant difference between the Pre intervention and Post intervention of Social skill: Listening response. It has been observed from the Fig. 3 that the difference between two means of pre intervention and post intervention was significant and it shows that the deficit in listening response is less in post intervention as compared to pre intervention. It signifies that Social Skill: Listening response can be enhanced by intervention of social stories. This result is also supported by study which was done by Delano and Snell (2006). This study includes 4 social skills including seeking attention, initiating comments, initiating requests and making contingent responses. The participants were 3 elementary students with autism. The intervention of social stories was consisted of reading individualized social stories, answering comprehension questions, and participating in a $10 \mathrm{~min}$ play session. The result indicates that social stories can work as an additional intervention to improve social skills and increase in social engagement and frequency of specific social skills. Listening response can be observed in a social skill of seeking attention.

Social stories of present research includes listening response as it involves story of initiating conversation which also includes listening to others and respond back to the questions asked by others. It has been observed that children were listening and responding back if their names were called. They do the specific tasks according to the instructions which signify that they were 
listening and understanding but not responding back to the other persons. All of the participants show improvement in listening response.

The analysis of Table 4 and Fig 4 shows that there is significant difference between the Pre intervention and Post intervention of Social skill: Visual response. It has been observed from the Fig.4 that the difference between two means of pre intervention and post intervention was significant and it shows that the deficit in visual response is less in post intervention as compared to pre intervention. It signifies that Social Skill: Visual response can be enhanced by intervention of social stories. These results are also supported by the research done by Schneider and Goldstein (2005). This study demonstrated that social stories, presented as an auditory-visual support system, were effective in increasing desired behaviors in three children with autism. It has been observed that through auditory and visual support system of social story, visual response could be enhanced. The results of this study indicate social stories were able to increase on-task behaviors for three children with autism. The stories were able to describe behaviors that were appropriate and required in social situations. After intervention, the participants were able to respond more appropriately and manage their behavior.

Social stories of present research were supported by auditory and visual system. Therefore, it can be easily observed that the eye contact of the participants were improved and maintained. In one of the participants, it has been observed that he start maintaining eye contact with the people or things which are close to him. All of the participants show significant improvement in visual response.

The analysis of Table 5 and Fig 5, it is seen that there is significant difference between Pre intervention and Post intervention of Social Skill: Verbal Communication by social stories. This result is also supported by the previous study by Reichow and Sabomie (2009). They did study which focused to analyze the effect of social stories on verbal greetings initiation of autistic children. Verbal greetings initiation is a part of social skills. A young 11 year old boy diagnosed with High Functioning Autism was participant. A comparative study was done with social stories intervention and withdrawal of social stories intervention. Improvement in verbal greetings initiation was observed in both intervention conditions as compared to baseline conditions. The result of the study indicated that the social stories can also be effective in increasing verbal greeting initiations in autistic children.

A classic recent research was done by Thiemann and Goldstein (2013) also contributes to our findings. In this study, written text and pictorial cuing (social stories) with supplemental video feedback was investigated to know the effects on social communication of autistic children. Results showed increase in targeted social communication skills when the treatment was implemented. Some generalized treatment effects were observed across untrained social behaviors. The strength which combined social stories, pictorial and written text cues with 
supplemental video feedback gives a positive or effective change in social communication skills of 5 young students with autism or social impairment.

In this research, social stories are made with the sentences and verbal prompts were also used which gives the idea of communication to the children. One of the Social stories included the initiation of conversation and replying to the questions asked by others which caters verbal communication as a social skill. It is observed that the participants show improvement in verbal communication but that was not so supportive for initiating a conversation. On the other hand, participants were start responding back to some of the questions.

It can be concluded from the above discussion that social skills of children with Autism Spectrum Disorder can be improve by the intervention of Social Stories. Social skills including relating to people, adaptation to change, visual response, listening response and verbal communication can be enhanced and supported by the Social Stories.

\section{CONCLUSION}

The present study focused on the impact of social stories on social skills of children with Autism Spectrum Disorder. For the purpose of the study, a comparative study was done between Pre intervention and Post intervention by using social stories. The data was collected on 4 samples, ranging from 4-8 years of age and diagnosed with Autism Spectrum Disorder.

Childhood Autism Rating Scale 2 (CARS2) was used as a tool to assess the social skills in Pre intervention and Post intervention phase. Social stories were developed according to common deficits of social skills in 4 children.

The hypotheses were formulated on the basis of the objectives of the study and the obtained score were analyzed by using $\mathrm{T}$ - test, statistical technique.

It is concluded from the present study that there is significant difference between the scores of social skill in pre intervention and post intervention by Social Stories. It signifies that there is impact of social stories on the social skill of children with Autism Spectrum disorder.

REFERENCES

Bell, N. J. (2005). Using Social Stories to Improve Socially Appropriate Behaviors in Children with Autism.

Carson, R.C., Butcher, J.N., Mineka, S., \& Hooley, J.M. (2007). Abnormal Psychology. (13 ${ }^{\text {th }}$ Ed.). Pearson Education Inc., New Delhi.

Reichow, B., \& Sabornie, E. J. (2009). Brief report: Increasing verbal greeting initiations for a student with autism via a Social Story ${ }^{\mathrm{TM}}$ intervention. Journal of autism and developmental disorders, 39(12), 1740-1743. 
Sadock, B.J., \& Sadock, V.A. (2007). Synopsis of Psychiatry. (10 ${ }^{\text {th }}$ Ed.). Lippincott Williams \& Wilkins, Philadelphia.

Schneider, N., \& Goldstein, H. (2009). Using social stories and visual schedules to improve socially appropriate behaviors in children with autism. Journal of Positive Behavior Interventions.

Simpson L. Richard, 2008. Autism Spectrum Disorder: Interventions and treatments for children and youth, (6 ${ }^{\text {th }}$ Edition) .Sage South Asia

\section{Online Links:}

Cohen, D. (2006). Developmental Psychopathology, Risk, Disorder, and Adaptation (2nd ed.) (D. Cicchetti, Ed.). John Wiley \& Sons. Retrieved from:

https://books.google.co.in/books?id=UlQjE-

Ka09sC\&pg=PA319\&dq=comorbidity + of + autism + spectrum + disorders + with + mental + retardation $\& h l=e n \& s a=X \& e i=e O A a V d n C L s 6 R u A T w l Y H g C A \& v e d=0 C C U Q 6 A E w A g \# v$ =onepage \&q=comorbidity $\% 20$ of $\% 20$ autism $\% 20$ spectrum $\% 20$ disorders $\% 20$ with $\% 20$ me ntal\%20retardation $\& f=$ false

Hollander, E. (2011). Textbook of Autism Spectrum Disorders (A. Kolevzon, Ed.). American psychiatric pub. Retrieved from: https://books.google.co.in/books? id =NgEg2FqxrYYC\&pg=PA209\&dq=pdf+comorbidity + of + autism + spectrum + disorders \&hl=en \&sa $=X \&$ ei $=y 9 I$ IV VezpAYqeugTWroDYDg \&ved $=0 C C Q Q 6 A E w A Q \# v=$ onepage $\& q=p d f \% 20$ comorbidity $\% 20$ of $\% 20$ autism $\% 20$ spectrum \%20disorders \&f=false

Leboyer, M. (2015). Autism Spectrum Disorder: Phenotype, Mechanism and Treatments (Vol.180) (P.Chaste, Ed.). Karger Medical and Scientific Publisher. Retrieved from :https://books.google.co.in/books?id=C1nBwAAQBAJ\&pg=PT175\&dq=comorbidity + of + autism + spectrum + disorders \&hl=en $\& s a=X \& e i=x d U a V a G 3 A t$ WIuASrkYDIDg\&ved $=0$ CCEQ6AEwAQ\#v=onepage \& $q=$ comorbidity\%20of\%20autism\%20spectrum\%20disorde $\underline{r s \& f=\text { false }}$ 


\section{ACKNOWLEDGEMENT}

I am thankful to my supervisor, Babita Prusty, for his guidance and suggestions which I required very much. He helped me to design, implement, apply, criticize and clearing the paths towards thesis completion in his solution oriented way.

I extend my appreciation to Dr. Harshita Misra for her unconditional support, guidance and encouragement.

I also extend my appreciation to Dr. Anand Jha for his unconditional support.

I would like to extend my heart filled gratitude to my parents Mr. Manoj Aggarwal and Mrs. Rekha Aggarwal for their unconditional love, help and support.

Last, but not the least my best friends and my classmates who have always been with me during the tenure of this project.

With great pleasure I express my deep gratitude to Prof. Abha Singh, for the decisive and energetic support provided throughout my study period. 